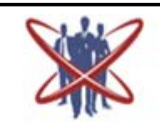

Open access Jumal International Journal of Emerging Trends in Science and Technology

DOI: https://dx.doi.org/10.18535/ijetst/v6i11.01

\title{
Original Research Article \\ Dental Malpractice in Implant Dentistry in Saudi Arabia: Preoperative and Intraoperative Complications
}

\author{
Authors \\ Rahaf Al-Safadi, ${ }^{1,2 *}$ Riham Al-Safadi, Reef Al-Safadi, Mohammed Al-Shulayyil, ${ }^{2}$ \\ Abdullah Al-Anazi, ${ }^{2}$ Malak Al-Momen, ${ }^{2}$ Sara Buarish, ${ }^{2}$ Sara Al-Duraye, ${ }^{2}$ \\ Hadeel Al-Otaibi, ${ }^{2}$ Abdullah Al-Shenaifi ${ }^{2}$ \\ ${ }^{1}$ Department of Preventive Dentistry, College of Dentistry, Riyadh Elm University, Riyadh, \\ Kingdom of Saudi Arabia \\ ${ }^{2}$ University Dental Hospital, College of Dentistry, Riyadh Elm University, Riyadh, \\ Kingdom of Saudi Arabia \\ *Corresponding Author \\ Rahaf Al-Safadi \\ Department of Preventive Dentistry, University Dental Hospital, College of Dentistry, \\ Riyadh Elm University, Riyadh, Kingdom of Saudi Arabia \\ Email: dent.sci.research@gmail.com
}

\begin{abstract}
Aim: The aim of this study was to detect preoperative and intraoperative dental malpractice in the field of implant dentistry in the Kingdom of Saudi Arabia.

Materials and Methods: 115 patients aged $\geq 18$ years with at least one professional malpractice in implant dentistry done in dental health premises in Saudi Arabia were included in the study. Clinical and radiographic examinations were used to detect preoperative complications (poor patient selection, diagnosis, inappropriate treatment planning) and intraoperative complications (damage to adjacent tooth, inferior alveolar nerve damage, sinus penetration, and implant positional failure due to poor surgical execution). The data obtained including age and gender were documented in a patient examination form then statistically analyzed using Chi-Square Test or Binomial Test and Spearman's Correlation Coefficient.

Results: More than half of the patients were females (62.6\%). The majority of the patients were in the age group 50-60 years (31.3\%). Also, the majority of the patients had implants with malpractice placed in the posterior region. Exactly half of the patients had implants with malpractice placed in the maxilla. In addition, exactly half of the patients had technical errors violating the surrounding structures; (39.1\%) of the patients had damage to adjacent tooth, (11.3\%) had inferior alveolar nerve damage, and (4.3\%) had sinus penetration.

Conclusion: Patients were equally divided between implant positional failure due to preoperative inappropriate treatment planning and that due to intraoperative poor surgical execution. Solid theoretical knowledge and polished surgical skills are key success factors for accurate implant placement.

Keywords: Implant, Intraoperative, Malpractice, Preoperative
\end{abstract}

\section{Introduction}

"Dental malpractice is the failure of a dental professional to follow the accepted standards of practice of his or her profession, resulting in harm to the patient. Usually, proof of failure to comply with

accepted standards of dental practice requires the testimony of someone with expertise in dentistry." There are many reasons for the increased number of complications and errors occurring in implant 
dentistry. For instance, the increase in the number of implants used over the past 10-15 years. ${ }^{2,3}$ Also, the increased number of dentists of different specialties and different experiences placing dental implants including those whose major specialties are aesthetics not periodontal or oral surgery. ${ }^{2}$ In addition, the insufficient preparation of undergraduate students in implant dentistry and the fact that many dentists receive their implant training from continuing education courses offered by implant companies or private practitioners which don't rise to the level of the comprehensive training that formal training programs offer, and thus practitioners are less competent and familiar with complications. Many dentists placing implants today lack the education, training, and experience that enable them to take the right decision and action to manage an implant complication when it occurs. ${ }^{2}$ Furthermore, dentists are placing implants in compromised sites and using aggressive protocols today which include implants placed at the same visit immediately after tooth extraction, "immediate provisionalization" of the implant after placement, and the occlusal loading of an implant on the same day of placement. ${ }^{2}$ Also, placing implants in compromised patients and or compromised sites where there isn't enough bone or soft tissue to properly place the implant. Moreover, Forum ${ }^{2}$ believes that the idealism of implant cases presented in lectures to an audience of dentists plays a passive role in the increased incidence of implant complications. Although it is agreed today that dental implants have high survival rates $\geq 90 \%$, it is still essential to point out to the precautions and complications associated with dental implantology. ${ }^{2}$ In 1989, Balshi ${ }^{4}$ identified and classified complications that arise with osseointegrated implants into six categories as the following: (1) esthetics, (2) phonetics, (3) functional, (4) biologic, (5) mechanical, and (6) ergonomic.

In 2004, the report of the American Dental Association Council on Scientific Affairs considered dental implants a treatment with high success rates, and recommended clinicians to adhere to the current best evidence when using implantation therapies and systems. It also recommended evaluators to employ common and consistent criteria when assessing the outcomes of dental implant treatments. ${ }^{5}$ The aim of this study was to detect preoperative and intraoperative malpractice in implant dentistry in Saudi Arabia.

\section{Materials and Methods \\ Ethical approval}

The study was registered with the research center of Riyadh Elm University (FRP/2019/110) and received ethical approval from the institutional review board of the same institution (RC/IRB/2019/190).

\section{Selection of the content for analysis and statistical analysis}

The classification of preoperative and intraoperative complications was adapted based on Chee and Jivraj, ${ }^{6}$ Chen and Buser, ${ }^{7}$ Pi-Anfruns, ${ }^{8}$ and Pinchi et $\mathrm{al}^{9}$ (Table 1).

Table 1: Classification of preoperative and intraoperative complications*

\begin{tabular}{|c|c|}
\hline Category & Item \\
\hline $\begin{array}{l}\text { Preoperative technical errors (errors during } \\
\text { diagnosis and treatment planning) }\end{array}$ & $\begin{array}{l}\square \text { Poor patient selection (eg, smoking, diabetes, } \\
\text { periodontitis, poor oral hygiene) } \\
\square \text { Diagnostic errors (eg, poor anatomical analysis of } \\
\text { implant site, poor occlusal analysis, such as interocclusal } \\
\text { space, opposing dentition, type of occlusion) } \\
\square \text { Inappropriate treatment planning (eg, incorrect number } \\
\text { of implants, incorrect dimension of implants, incorrect } \\
\text { spacing of implants, incorrect length of implants) }\end{array}$ \\
\hline $\begin{array}{l}\text { Intraoperative technical errors (technical } \\
\text { operative errors during implant placement) }\end{array}$ & $\begin{array}{l}\square \text { Damage to adjacent tooth } \\
\square \text { Inferior alveolar nerve damage } \\
\square \text { Sinus penetration } \square \text { Implant positional failure } * *\end{array}$ \\
\hline
\end{tabular}

*Some cases had more than one detection of claimed error.

** Implant positional failure due to poor surgical execution 

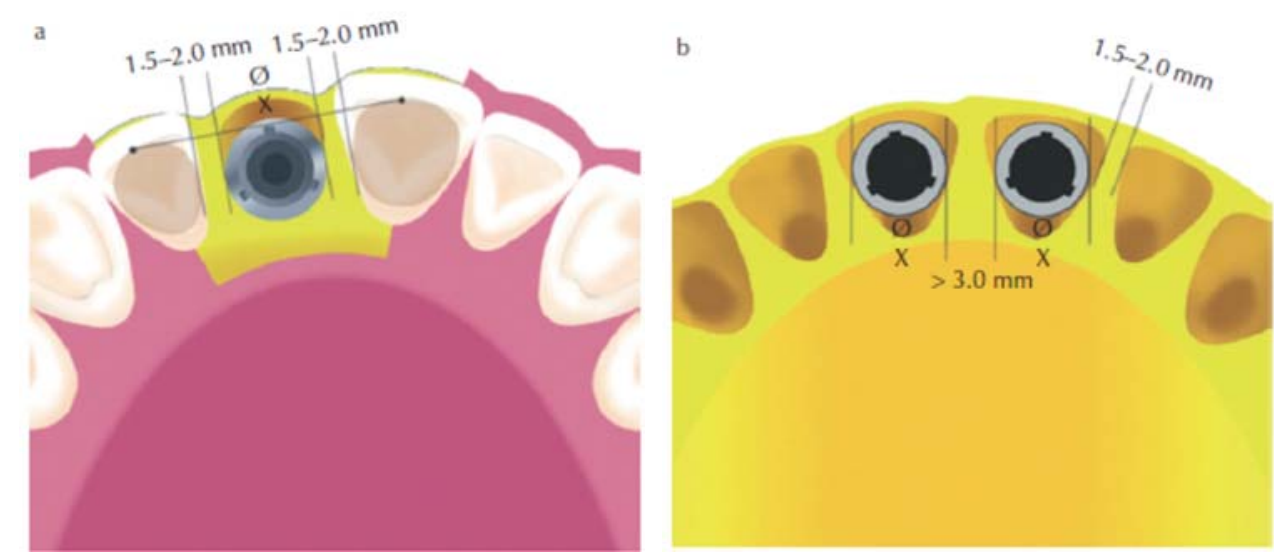

Figure 1. $(\mathrm{a}, \mathrm{b})$ Mesio-distal space guidelines for correct implant placement Source: John Wiley \& Sons, $2014^{10}$

Also, based on Byrne, ${ }^{10}$ the following spatial considerations and safety guidelines were followed for the detection of implant malpractice cases:

\section{Mesio-distal space between implants / between} implants and adjacent crowns and roots

A mesio-distal space of 1.5-2.0 mm of bone should be between the greatest diameter of the implant and the crowns and roots of adjacent teeth with a minimum of 1.0 to $1.5 \mathrm{~mm}$ of space mesially and distally (Figure 1). ${ }^{10}$ In the present study, insufficient distance from the adjacent tooth to the implant less than $1.0 \mathrm{~mm}$ was considered for the detection of errors. "A bone thickness of between 2.0 and $3.0 \mathrm{~mm}$ is recommended between two adjacent implants." 10 (Figure 1)

\section{Vertical space for implant prosthesis (crown / denture) from occlusal contact to implant \\ platform}

For crowns and bridges, a space of 5.0-7.0 $\mathrm{mm}$ or $5.0-8.0 \mathrm{~mm}$ with a minimum of $5.0 \mathrm{~mm}$ between the implant platform and the opposing teeth is preferable. Also, to fabricate an implant overdenture, a distance of 10.0-12.0 mm with a minimum of $10.0 \mathrm{~mm}$ from the implant platform or the bony ridge crest to the occlusal plane is required. ${ }^{10}$

\section{Bucco-lingual bone volume}

At least $1.0 \mathrm{~mm}$ of bone should remain buccally and lingually after implant insertion to prevent bone dehiscence or fenestration during surgery. For narrow ridges, ridge grafting should be considered. ${ }^{10}$

\section{Implant position: Aesthetic and safety guidelines:}

\footnotetext{
- Ensure that the implant platform is flush with the alveolar bone crest (which may need flattening). Polished necks are designed to extend above the crest.

- Between 1.0 and $2.0 \mathrm{~mm}$ of bone should surround the implant bucco-lingually and mesio-distally.

- Between 2.0 and $3.0 \mathrm{~mm}$ of bone should remain between adjacent implant platforms.

- The implant must be positioned at least $2.0 \mathrm{~mm}$ away from nerve canals.

- Between 1.0 and $2.0 \mathrm{~mm}$ bone should remain between the implant and the maxillary antrum, the floor of the nose, and the mandiblular inferior border or cortical plates.

- Allow $5.0 \mathrm{~mm}$ between an anterior implant and the mental foramen to allow for the posterior loop of the mental nerve. ${ }^{10}$
}

The inclusion criteria applied for case selection were: (1) patients aged $\geq 18$ years (2) patients with at least one professional malpractice in implant dentistry (3) professional malpractice in implant dentistry of the substandard dental implant treatments done in dental health premises (hospitals, polyclinics, private clinics) in the Kingdom of Saudi Arabia. The exclusion criterion was: cases with unacceptable diagnostic quality of radiographs. The sample of the study was randomly selected. The term case was used in this study to indicate to one patient with at least one implant malpractice, and some cases had more than one detection of claimed error. The study was conducted from September 
2019 to November 2019. The patient consent was taken on an informed consent statement form for clinical studies. Clinical and radiographic examinations were applied including panoramic and periapical radiographs in addition to threedimensional imaging CBCT. All cases were subjected to consultations of experienced implantologists. The data obtained including age and gender were documented in a patient examination form then statistically analyzed using Chi-Square Test or Binomial Test to test the contingency of the variables and Spearman's Correlation Coefficient to test the association between categorical variables. All statistical analyses were performed using the IBM SPSS Statistics version 20 data processing software. The significance level was set at $\mathrm{p}<0.05$.

Table 2: Distribution of patients by the number of implants

\begin{tabular}{|l|c|}
\hline $\begin{array}{l}\text { Number of implants } \\
\text { with malpractice }\end{array}$ & $\mathrm{n}(\%)$ \\
\hline One implant & $74(64.3)$ \\
Two implants & $28(24.3)$ \\
Three implants & $7(6.1)$ \\
Four implants & $3(2.6)$ \\
Five implants & $2(1.7)$ \\
$\geq$ Six implants & $1(0.9)$ \\
Total & $115(100)$ \\
\hline
\end{tabular}

Implant Malpractice and Patients' Gender and Age

Chi-Square Test showed that there was a significant difference between the percentage of female patients $\mathrm{n}=72(62.6 \%)$ and that of male patients $\mathrm{n}=43$ $(37.4 \%) \mathrm{p}=0.007<0.05$. Also, Chi-Square Test showed that there was a significant difference in the percentages of patients distributed by different age groups $p=0.004<0.05$ (Table 3$)$.

Jaw

Chi-Square Test showed an insignificant difference between the percentage of patients who had implants with malpractice placed in the maxilla and

\section{Results}

On the basis of the well-defined predetermined spatial considerations and safety guidelines, the inclusion criteria, and the exclusion criterion, of 954 implant dentistry cases, 115 cases were selected. The total number of implants that showed error was 181 dental implants. The mean number of dental implants with malpractice was (mean $=1.57 \pm 1.052$ ) range [1-8].

\section{Patients and the Number of Dental Implants}

Chi-Square Test showed that there was a significant difference in the percentages of patients distributed by the number of dental implants with malpractice $\mathrm{p}=0.000<0.05$. One or two implants were inserted in $88.6 \%$ of patients; $97.3 \%$ of patients received up to four implants (Table 2).

Table 3: Distribution of patients by age groups

\begin{tabular}{|c|c|}
\hline $\begin{array}{l}\text { Age } \\
\text { Group, } \\
\text { Years }\end{array}$ & $\mathrm{n}(\%)$ \\
\hline$<30$ & $12(10.4)$ \\
$30-40$ & $28(24.3)$ \\
$41-49$ & $22(19.1)$ \\
$50-60$ & $36(31.3)$ \\
$>60$ & $17(14.8)$ \\
Total & $115(100)$ \\
\hline
\end{tabular}

that of patients who had them placed in the mandible $p=0.587>0.05$. Therefore, the two aforementioned percentages were equally divided.

\section{Implant Malpractice and Region}

Chi-Square Test was used to test the significance of differences in the percentages of patients with respect to region (Table 4). Also, Chi-Square Test showed that there was a significant difference between the percentage of patients who had implants with malpractice placed in the posterior region $\mathrm{n}=100(81.3 \%)$ and that of patients who had them placed in the anterior region $\mathrm{n}=23(18.7 \%)$ $\mathrm{p}=0.000<0.05$. 


\section{Preoperative Complications}

Chi-Square Test was used to test the significance of differences in the percentages of patients with respect to poor patient selection, diagnosis, and inappropriate treatment planning (Table 5). Also, Binomial Test showed that the percentage of patients who had implant malpractice due to diabetes was equal to that of patients who had it due to poor oral hygiene $=50 \%$ as the difference from the test proportion 0.50 was insignificant $p=0.453$ $>0.05$.
Table 4: Distribution of patients by regions

\begin{tabular}{|c|c|c|}
\hline Region & n (\%) & p-value \\
\hline $\begin{array}{l}\text { Anterior } \\
\text { Yes Malpractice } \\
\text { No Malpractice } \\
\text { Total }\end{array}$ & $\begin{array}{l}23(20) \\
92(80) \\
115(100)\end{array}$ & $\begin{array}{c}\mathrm{p}=0.000<0.05 \\
\text { significant } \\
\text { difference }\end{array}$ \\
\hline $\begin{array}{l}\text { Posterior } \\
\text { Yes Malpractice } \\
\text { No Malpractice } \\
\text { Total }\end{array}$ & $\begin{array}{l}100(87) \\
15(13) \\
115(100)\end{array}$ & $\begin{array}{c}\mathrm{p}=0.000<0.05 \\
\text { significant } \\
\text { difference }\end{array}$ \\
\hline
\end{tabular}

Table 5: Distribution of patients by types of preoperative complications

\begin{tabular}{|l|c|c|}
\hline Type of Preoperative Complication & $\mathrm{n}(\%)$ & $\mathrm{p}$-value \\
\hline Poor Patient Selection & $7(6.1)$ & $\mathrm{p}=0.000<0.05$ \\
Yes & $108(93.9)$ & significant difference \\
No & $115(100)$ & \\
Total & $72(62.6)$ & $\mathrm{p}=0.007<0.05$ \\
\hline Diagnosis & $43(37.4)$ & significant difference \\
Yes & $115(100)$ & \\
No & & \\
Total & $96(83.5)$ & $\mathrm{p}=0.000<0.05$ \\
\hline Inappropriate Treatment Planning & $19(16.5)$ & significant difference \\
Yes & $115(100)$ & \\
No & & \\
Total & \\
\hline
\end{tabular}

\section{Intraoperative Complications}

\section{Violation of surrounding structures}

Chi-Square Test showed that there was an insignificant difference between the percentage of patients who had technical errors violating the surrounding structures and that of patients who didn't have them $p=0.641>0.05$. Therefore, the two aforementioned percentages were equally divided.

Also, Chi-Square Test was used to test the significance of differences in the percentages of patients with respect to damage to adjacent tooth, inferior alveolar nerve damage, invasion of maxillary sinus (sinus penetration) (Table 6).

Violation of surrounding structures and age and gender

At the patient level, Spearman's Correlation Coefficient showed that there was an insignificant relationship between each of the sinus penetration, the inferior alveolar nerve damage, the damage to adjacent tooth and the gender of the patient $p=$
$0.078>0.05, \mathrm{p}=0.261>0.05, \mathrm{p}=0.475>0.05$, respectively. Also, at the patient level, Spearman's Correlation Coefficient showed that there was an insignificant relationship between each of the sinus penetration, the inferior alveolar nerve damage, the damage to adjacent tooth and the age of the patient $p$ $=0.270>0.05, \mathrm{p}=0.351>0.05, \mathrm{p}=0.705>0.05$, respectively.

\section{Implant positional failure}

Chi-Square Test showed that there was a significant difference between the percentage of patients who had intraoperative implant positional failure $n=93$ $(80.9 \%)$ and that of patients who didn't have it $\mathrm{n}=$ $22(19.1 \%) \mathrm{p}=0.000<0.05$. Also, Chi-Square Test showed that there was an insignificant difference between the percentage of patients who had implant positional failure due to preoperative inappropriate treatment planning and that of patients who had it due to intraoperative poor surgical execution $\mathrm{p}=$ $0.827>0.05$. 
Table 6: Distribution of patients by types of violation of surrounding structures

\begin{tabular}{|l|c|c|}
\hline Type of Violation of Surrounding Structures & $\mathrm{n}(\%)$ & $\mathrm{p}$-value \\
\hline Damage to Adjacent Tooth & & \\
Yes & $45(39.1)$ & $\mathrm{p}=0.020<0.05$ \\
No & $70(60.9)$ & significant difference \\
Total & $115(100)$ & \\
\hline Inferior Alveolar Nerve Damage & $13(11.3)$ & $\mathrm{p}=0.000<0.05$ \\
Yes & $102(88.7)$ & significant difference \\
No & $115(100)$ & \\
Total & & \\
\hline Sinus Penetration & $5(4.3)$ & $\mathrm{p}=0.000<0.05$ \\
Yes & $110(95.7)$ & significant difference \\
No & $115(100)$ & \\
Total & \multicolumn{2}{|}{} \\
\hline
\end{tabular}

\section{Discussion}

\section{Comparison with Literature}

In Italy and in Romania, Pinchi et $\mathrm{al}^{9}$ and Clark et $\mathrm{al}^{11}$ found 121 and 160 cases of implant malpractice, respectively; the total number of dental implants with malpractice in the two studies was 411 and 454, respectively; in Romania, the average number of dental implants with error placed per patient was $2.86 \pm 1.97$ with (range 1-9). ${ }^{11}$ The number of patients who received one or two implants with malpractice was higher in the present study than in Italy $^{9}(88.6 \%)$ and $(49.6 \%)$, respectively; however, in both studies, over $90 \%$ of patients received up to four implants with malpractice $(97.3 \%)$ and (92.6\%), respectively. ${ }^{9}$ In the present study and in Italy, ${ }^{9}$ of all age groups, the highest percentage of cases was seen in the age group 50-60 years (31.3\%) and $(60.3 \%)$, respectively; also, of all age groups, patients $>60$ years of age $(14.8 \%$ and $28.1 \%)$ were more than patients $<30$ years of age $(10.4 \%$ and $0.8 \%$ ), respectively. In the present study, in exactly half of the cases examined, the maxilla was involved in the malpractice; however, in Italy and in Romania, it was involved in over half of the cases $n$ $=65(53.7 \%)$ and $\mathrm{n}=94$ (58.7\%), respectively. ${ }^{9,11}$ In addition, in consistence with the two aforementioned studies, the present study found that more than half of the patients with malpractice were females. For instance, in Italy, females were $\mathrm{n}=89$ $(73.6 \%)$, and males were $\mathrm{n}=32(26.4 \%)^{9}$; in Romania, females were $\mathrm{n}=91(57.5 \%)$, and males were $n=67(42.4 \%) .{ }^{11}$ Furthermore, in agreement with the present study, Clark et $\mathrm{al}^{11}$ found that patients who had implants placed in the posterior region were more $n=131(66.1 \%)$ than those who had implants placed in the anterior region $n=67$ (33.8\%). Moreover, in accordance with the present study, Pinchi et $\mathrm{al}^{9}$ found that half of the patients $\mathrm{n}$ $=61(50.4 \%)$ had technical errors involving the surrounding structures. Also, Clark et al ${ }^{11}$ found that of 160 cases with implant malposition complications, 62 cases revealed penetration of the implant to adjacent anatomic structure plus 15 cases of adjacent tooth injury; therefore, roughly half of the cases $n=77$ (48.1\%) had implant malpractice violating the anatomic surrounding structures. For the purpose of comparison with Clark et al, ${ }^{11}$ we intended to recalculate the percentages of the cases of adjacent tooth injury $\mathrm{n}=15$, inferior alveolar nerve canal penetration $\mathrm{n}=9$, and sinus penetration $\mathrm{n}=21$ out of 160 cases. Consequently, the percentage of sinus penetration cases was the highest in Romania and the lowest in the present study. In addition, the percentage of inferior alveolar nerve damage cases was the highest in Italy and the lowest in Romania. (Table 7). 
Table 7: Violation of surrounding structures in Italy, in Romania, and in the present study

\begin{tabular}{|c|c|c|c|}
\hline Reference & $\begin{array}{c}\text { Damage to } \\
\text { Adjacent Tooth } \\
\mathrm{n}(\%)\end{array}$ & $\begin{array}{c}\text { Inferior Alveolar } \\
\text { Nerve Damage } \\
\mathrm{n}(\%)\end{array}$ & $\begin{array}{c}\text { Sinus } \\
\text { Penetration } \\
\mathrm{n}(\%)\end{array}$ \\
\hline Present study & $45(39.1)$ & $13(11.3)$ & $5(4.3)$ \\
\hline Pinchi et al & $8(6.6)^{* *}$ & $39(32.2)$ & $11(9.1)$ \\
\hline Clark et al $^{11 *}$ & $15(9.3)$ & $9(5.6)$ & $21(13.1)$ \\
\hline
\end{tabular}

* frequencies (n) are from original reference, but percentages are recalculated out of 160 cases for the purpose of comparison with the present study.

**Pulpal dental necrosis of an adjacent tooth near the implant site

\section{Patient Selection}

The presence of any acute oral infection is an absolute contraindication to implant therapy. In addition, breath odor may reflect poor oral hygiene, smoking, or diabetes ketosis. ${ }^{10}$

Patients who have untreated periodontal disease should not receive implants because of the possibility of infection of the implant surfaces from preexisting periodontopathic bacteria ${ }^{12}$ which are highly prevalent in peri-implantitis. ${ }^{13}$ The highest risk for implant failure is associated with periodontitis followed by tobacco smoking. ${ }^{14}$ Many studies have tested the impact of smoking on the implant survival rate and failure rate, and almost all of those studies confirmed the negative effect of smoking on implant therapy. The degree of smoking exposure (the number of cigarettes smoked and the duration of smoking), the anatomic location of implant placement whether in the maxilla or in the mandible or near augmented sinuses or ridges, and the implant surface are factors found to have a substantial impact on the effect of smoking on implant therapy outcomes. ${ }^{15}$ For instance, an increased failure rate is observed in smokers when compared with nonsmokers with a failure rate 2-2.5 times higher in smokers, ${ }^{15}$ and heavy smokers have been found very good candidates for implant failure. ${ }^{12}$ Also, implants placed in the maxilla are more susceptible to smoking than implants placed in the mandible. In addition, implants placed in sites augmented by bone grafting have survival rates similar to those implants placed in sites of native bone; however, smoking may be a major factor in diverting the outcome of implant therapy in augmented sites. Regarding implant surface, smoking negatively affects the survival of machined surface implants to a greater degree than rough surface implants, and rough or microroughened surface characteristics of dental implants may alleviate the negative side effects of smoking on long-term implant outcomes. ${ }^{15}$

Diabetes affects the vasculature, healing, and susceptibility to infection. ${ }^{12,15}$ Also, poorly controlled diabetes is a major risk factor for periimplant bone loss. ${ }^{10}$ There is no scientific evidence of increased implant failure rate in well-controlled diabetic patients, but diabetes should be considered as an important risk factor to implant complications and failure in individuals with poor glycemic control. $^{12,15}$

Although cardiovascular disease such as hypertension, atherosclerosis, vascular stenosis, coronary artery disease, and congestive heart failure have direct impact on oxygen and nutrition supply to tissues, the study of Khadivi et al ${ }^{16}$ which had a small sample size suggested that cardiovascular disease may not be a risk factor for successful osseointegration.

Moy et $\mathrm{al}^{17}$ found that diabetes and tobacco smoking were significant predictors to implant failure, and failure rates significantly increased in smokers and diabetic patients; however, asthma and hypertension were not correlated with a significant increase in failure of dental implants.

Patients with osteoporosis are not contraindication to implant therapy, ${ }^{12,15,18-20}$ and some authors stated that the osteoporotic bone is similar to the proposed model of bone type IV. ${ }^{12,20}$ In addition, the risk of osteonecrosis is low with oral bisphosphonates which is an antiresorptive medication, ${ }^{12,20}$ but intravenous bisphosphonates is contraindication to implant therapy ${ }^{12,15}$ as well as radiotherapy because 
of the high risk of steonecrosis. ${ }^{12,15,17}$

\section{Implant Positional Failure}

The most common type of implant positional failure occurs due to poor treatment planning and or poor surgical execution. ${ }^{6,11}$ Implant malposition can be avoided preoperatively by proper early diagnosis followed by appropriate treatment planning. For example, using CBCT whenever there is need for extensive information such as ridge width, bone volume, and anatomic structures then choosing the correct implant diameter and length. ${ }^{21}$ In addition, it can be avoided intraoperatively by not trying to attempt any intraoperative surgical jeopardy whenever bone volume is insufficient, instead aborting the operation..$^{8,10,22}$ In order to achieve a correct insertion of an implant in a three dimensional position, a clinician must be competent and skillful to precisely execute a defined treatment plan. ${ }^{7}$ Dental practitioners can better match cases to their skills and level of experience by using the SAC classification (straightforward, advanced, complex). ${ }^{7,10,23}$

\section{Damage to Adjacent Tooth}

Tooth roots are anatomic structures that should be taken seriously. ${ }^{10}$ Damage to adjacent tooth can lead to loss of vitality of a given tooth and may require root canal therapy or even extraction. ${ }^{8}$ Even if the crowns were ideally spaced, the roots could impinge. Therefore, it is wise to consider the need for orthodontics to correct crown or root alignment, or the size of spaces.

\section{Nerve Damage}

"In dental implantology, altered sensation results from trauma to branches of the mandibular nerve, including the inferior alveolar, mental, and lingual nerves". ${ }^{24}$

Intraoperative nerve damage can occur due to mucoperiosteal flap elevation or osteotomy during site preparation to receive the implant. ${ }^{8,24}$ To a great extent, neural traumatic injury occurs to the mental nerve during preparation and manipulation of the surgical flap. ${ }^{24}$

Several studies have reported a prevalence of (34\%$37 \%$ ) of altered sensation after implant placement in the mandible, ${ }^{24-26}$ and indicated that (10\%-15\%) of those cases may not resolve. ${ }^{24,25}$ Also, lip and chin are the most common combination for patient suffering sensory changes after implant placement in the mandible. ${ }^{24-26}$ The main symptom of altered sensation is numbness (68\%); eating (26\%), drinking (29\%), and speaking (38\%) are also affected; pain and drooling also occur (29\%) and (10\%), respectively. ${ }^{24}$ In general, (90\%) of transient sensory changes resolve by 6 months. ${ }^{24,25}$ However, it is important to inform patients about the possible risks prior to surgery because although the majority of patients may not feel that the disadvantages of altered sensation overweigh the advantages of implant placement, ${ }^{24,25}$ it was found that $8 \%$ of the patients who suffered nerve injury reported that they would not go under the same implant surgery. ${ }^{24}$

After implant placement in the mandible, in Adelaide, Australia and in Toronto, Canada, Ellies and Hawker ${ }^{24}$ and Ellies ${ }^{25}$ found that women were more prone to altered sensation than men, but Walton $^{26}$ didn't find a significant difference between men and women with respect to sensory changes. In addition, Ellies and Hawker ${ }^{24}$ found that age didn't affect the outcome of altered sensation after implant placement in the mandible.

\section{Invasion of the Maxillary Sinus}

Literature encourages vertical bone height of at least $5 \mathrm{~mm}$ beneath the sinus to gain primary stability and higher survival rates. ${ }^{27}$ For instance, Rosen et $\mathrm{al}^{28}$ found that the survival rate of implants was $96 \%$ or higher when ridge bone height was $5 \mathrm{~mm}$ or more, but it dropped to $(85.7 \%)$ when the crestal height was $4 \mathrm{~mm}$ or less. Also, Toffler ${ }^{29}$ found that the implant survival rate was $(93.5 \%)$ for ridge bone height $5 \mathrm{~mm}$ or more, while it dropped to $(73.3 \%)$ with a ridge bone height of $4 \mathrm{~mm}$ or less. In addition, implants displaced in the sinus were seen in cases with ridge bone height less than $5 \mathrm{~mm}$ which occurred during healing. ${ }^{30,31}$ Whether the implant displacement occurred intraoperatively during operation or postoperatively during graft maturation, it is highly important to retrieve the implant from the sinus to avoid inflammatory complications. ${ }^{30}$ Complications can be reduced by proper case selection, good surgical technique, and immediate handling of intraoperative and postoperative complications when they occur. ${ }^{32}$ 
The major intraoperative complication involving sinus elevation/augmentation is the Schneiderian membrane perforation with occurrence of $(5.5 \%$ $56 \%$ ) (Table 8). ${ }^{33-38}$ Perforation of the Schneiderian membrane during sinus augmentation procedures could occur during the elevation of the Schneiderian membrane (too rapid elevation of the membrane or elevation of the Schneiderian membrane beyond its capacity to adapt). Also, the sharp nature of some of the particulate graft materials placed into the osteotomy and or overpacking of the graft material could also cause the perforation of the sinus membrane. ${ }^{8,27}$

The usual sinus membrane elevation is 4 to $5 \mathrm{~mm},{ }^{39}$ but Reiser et $\mathrm{al}^{39}$ recommended the osteotome technique -minimal invasive sinus lift- to be useful in elevation beyond the aforementioned. Also, Baumann and Ewers ${ }^{34}$ raised the bar and reported two successful cases with at least $10 \mathrm{~mm}$ of sinus membrane elevation by using the osteotome technique. Therefore, the clinician must possess the clinical knowledge, experience, and surgical skills to be able to plan and execute depending on each individual case.

Reiser and colleagues classified the sinus membrane perforations into two classes: "Class I $(\leq 2 \mathrm{~mm}$ with exposure of the implant into the sinus cavity and loss of doming); Class II perforations ( $\geq 2 \mathrm{~mm}$ ) were associated with proximity of the osteotomy site to the medial wall of the sinus or the presence of septae." 39 They concluded that class I perforation has good prognosis, and the membrane withholds the elevated space as well as the dome shape once the implant is placed. However, class II perforation results in an exposed implant to the sinus cavity along with loss of space and dome shape. Therefore, in class II perforation, the clinician must interfere to close the perforation either with collagen, followed by grafting, and primary closure of the flap or with lateral window approach for surgical repair along with cessation of the implant placement. In small perforations, the patient should be given systemic antibiotics with antihistamine and instructed to avoid blowing the nose. ${ }^{27}$

Table 8: Review of current literature for the occurrence of Schneiderian membrane perforation as mentioned in actual references

\begin{tabular}{|c|c|c|c|}
\hline Reference & $\begin{array}{c}\text { Total number of } \\
\text { sinus augmentation } \\
\text { procedures } \\
\text { sinuses / patients } \\
(\mathrm{n})\end{array}$ & $\begin{array}{c}\text { Number of sinus } \\
\text { membrane } \\
\text { perforations } \\
\text { sinuses / patients } \\
\text { (n) }\end{array}$ & $\begin{array}{c}\text { Percentage of sinus } \\
\text { membrane perforations } \\
\text { sinuses / patients }\end{array}$ \\
\hline $\begin{array}{c}\text { Schwartz-Arad et } \\
\mathrm{al}^{33}\end{array}$ & $81 / 70$ & $36 / ?$ & $(\%)$ \\
\hline $\begin{array}{c}\text { Baumann and } \\
\text { Ewers }\end{array}$ & $? / 7$ & $? / 1$ & $? \% \% / ?$ \\
\hline Khoury $^{35}$ & $216 / 216$ & $? / 51$ & $? \% / 23.6 \%$ \\
\hline Nkenke et al ${ }^{36}$ & $18 / 14$ & $1 / 1$ & $5.5 \% / 7.1 \%$ \\
\hline Kasabah et al ${ }^{37}$ & $146 / 118$ & $82 / ?$ & $56.1 \% / ?$ \\
\hline Stricker et al ${ }^{38}$ & $66 / 41$ & $25 / 19$ & $37.8 \% / 46.3 \%$ \\
\hline
\end{tabular}

? Not specified in original reference

Whether the implant violated the inferior alveolar nerve canal or the maxillary sinus, it is essential to act immediately by unscrewing the implant, thus decreasing the implant depth or even completely removing it. "When in doubt, back it out."22

\section{Conclusion}

The results of this study indicated that the percentages of patients were equally divided between implant positional failure due to preoperative inappropriate treatment planning and that due to intraoperative poor surgical execution. Patient's safety and interest are priority; therefore, dentists must respect their limit of practice each 
time they attempt to place dental implants. Solid theoretical knowledge and polished surgical skills are key success factors.

\section{Funding: None \\ Conflict of Interest: None declared}

\section{References}

1. Dental Malpractice Law and Legal Definition. USLegal. https://definitions.uslegal.com/d/dentalmalpractice/. Accessed November 04, 2019.

2. Forum SJ. Implant complications: scope of the problem. In: Forum SJ, editor. Dental Implant Complications: Etiology, Prevention, and Treatment. Oxford: Wiley-Blackwell; 2010:1-8.

3. Murray CM, Thomson WM, Leichter JW. Dental implant use in New Zealand: a 10-year update. $N Z$ dent J. 2016;112(2):49-54.

4. Balshi TJ. Preventing and resolving complications with osseointegrated implants. Dent Clin North Am. 1989;33(4):821-868.

5. ADA Council on Scientific Affairs. Dental endosseous implants: an update. $J$ Am Dent Assoc. 2004;135(1):92-97.

6. Chee W, Jivraj S. Failures in implant dentistry. $\mathrm{Br}$ Dent J. 2007;202(3):123-129.

7. Chen ST, Buser D. Esthetic complications due to implant malpositions: etiology, prevention, and treatment. In: Forum SJ, editor. Dental Implant Complications: Etiology, Prevention, and Treatment. Oxford: Wiley-Blackwell; 2010:134155.

8. Pi-Anfruns J. Complications in implant dentistry. Alpha Omegan. 2014;107(1):8-12.

9. Pinchi V, Varvara G, Pradella F, Focardi M, Donati MD, Norelli G. Analysis of professional malpractice claims in implant dentistry in Italy from insurance company technical reports, 2006 to 2010. Int J Oral Maxillofac Implants. 2014;29(5):11771184.

10. Byrne G, ed. Fundementals of Implant Dentistry. Ames, Iowa: John Wiley \& Sons; 2014.

11. Clark D, Barbu H, Lorean A, Mijiritsky E, Levin

L. Incidental findings of implant complications on postimplantation CBCTs: a cross-sectional study. Clin Implant Dent Relat Res. 2017;19(5):776-782.
12. Palmer RM, Howe LC, Palmer PJ, eds. Implants in Clinical Dentistry. $2^{\text {nd }}$ ed. London: Informa Healthcare; 2012.

13. Persson GR, Renvert S. Cluster of bacteria associated with peri-implantitis. Clin Implant Dent Relat Res. 2014;16(6):783-793.

14. Buhara O, Pehlivan S. Estimating the importance of significant risk factors for early dental implant failure: a Monte Carlo simulation. Int J Oral Maxillofac Implants. 2018;33(1):161-168.

15. Rose LF, Mealey BL. Implant complications associated with systemic disorders and medications. In: Forum SJ, editor. Dental Implant Complications: Etiology, Prevention, and Treatment. Oxford: Wiley-Blackwell; 2010:9-45.

16. Khadivi V, Anderson J, Zarb GA. Cardiovascular disease and treatment outcomes with osseointegration surgery. J Prosthet Dent. 1999; 81(5):533-536.

17. Moy PK, Medina D, Shetty V, Aghaloo TL. Dental implant failure rates and associated risk factors. Int $J$ Oral Maxillofac Implants. 2005;20(4):569-577.

18. Wagner F, Schuder K, Hof M, Heuberer S, Seemann R, Dvorak G. Does osteoporosis influence the marginal peri-implant bone level in female patients? A cross-sectional study in a matched collective. Clin Implant Dent Relat Res. 2017;19(4):616-623.

19. Walter C, Al-Nawas B, Wolff T, Schiegnitz E, Grötz KA. Dental implants in patients treated with antiresorptive medication - a systematic literature review. Int J Implant Dent. 2016;2(1):9.

20. Venkatakrishnan CJ, Bhuminathan S, Chandran CR, Poovannan S. Dental implants in patients with osteoporosis - a review. Biomed Pharmacol J. 2017;10(3):1415-1418.

21. Elian N, Ehrlich B, Kim GU. Complications associated with implant planning: etiology, prevention, and treatment. In: Forum SJ, editor. Dental Implant Complications: Etiology, Prevention, and Treatment. Oxford: WileyBlackwell; 2010:46-70.

22. Zinman EJ. Medicolegal issues related to implant complications. In: Forum SJ, editor. Dental Implant Complications: Etiology, Prevention, and 
Treatment. Oxford: Wiley-Blackwell; 2010:429438.

23. Dawson A, Chen $\mathrm{S}$, editors. The $S A C$ classification in implant dentistry. Berlin: Quintessence Publishing; 2009.

24. Ellies LG, Hawker PB. The Prevalence of altered sensation associated with implant surgery. Int J Oral Maxillofac Implants. 1993;8(6):674-679.

25. Ellies LG. Altered sensation following mandibular implant surgery: a retrospective study. $J$ Prosthet Dent. 1992;68(4):664-671.

26. Walton JN. Altered sensation associated with implants in the anterior mandible: a prospective study. J Prosthet Dent. 2000;83(4):443-449.

27. Rosen PS. Complications with the bone-added osteotome sinus floor elevation: etiology, prevention, and treatment. In: Forum SJ, editor. Dental Implant Complications: Etiology, Prevention, and Treatment. Oxford: WileyBlackwell; 2010:310-324.

28. Rosen PS, Summers R, Mellado JR, Salkin LM, Shanaman RH, Marks MH. The bone-added osteotome sinus floor elevation technique: multicenter retrospective report of consecutively treated patients. Int $J$ Oral Maxillofac Implants. 1999;14(6):853-858.

29. Toffler M. Osteotome-mediated sinus floor elevation: a clinical report. Int J Oral Maxillofac Implants. 2004;19(2):266-273.

30. Misch K, Wang HL. Implant surgery complications: etiology and treatment. Implant Dent. 2008;17(2):159-166.

31. Peleg M, Garg AK, Mazor Z. Predictability of simultaneous implant placement in the severely atrophic posterior maxilla: a 9-year longitudinal experience study of 2,132 implants placed into 731 human sinus grafts. Int J Oral Maxillofac Implants. 2006;21(1):94-102.
32. Wallace SS. Complications in lateral window sinus elevation surgery. In: Forum SJ, editor. Dental Implant Complications: Etiology, Prevention, and Treatment. Oxford: Wiley-Blackwell; 2010:284309.

33. Schwartz-Arad D, Herzberg R, Dolev E. The prevalence of surgical complications of the sinus graft procedure and their impact on implant survival. J Periodontol. 2004;75(4):511-516.

34. Baumann A, Ewers R. Minimally invasive sinus lift. Limits and possibilities in the atrophic maxilla. Mund Kiefer Gesichtschir. 1999;3(Suppl 1):S70S73.

35. Khoury F. Augmentation of the sinus floor with mandibular bone block and simultaneous implantation: a 6-year clinical investigation. Int $J$ Oral Maxillofac Implants. 1999;14(4):557-564.

36. Nkenke E, Schlegel A, Schultze-Mosgau S, Neukam FW, Wiltfang J. The endoscopically controlled osteotome sinus floor elevation: a preliminary prospective study. Int J Oral Maxillofac Implants. 2002;17(4):557-566.

37. Kasabah S, Krug J, Šimůnek A, Lecaro MC. Can we predict maxillary sinus mucosa perforation?. Acta Medica (Hardec Králóve). 2003;46(1):19-23.

38. Stricker A, Voss PJ, Gutwald R, Schramm A, Schmelzeisen R. Maxillary sinus floor augmention with autogenous bone grafts to enable placement of SLA-surfaced implants: preliminary results after 15-40 months. Clin Oral Implant Res. 2003;14(2):207-212.

39. Reiser GM, Rabinovitz Z, Bruno J, Damoulis PD, Griffin TJ. Evaluation of maxillary sinus membrane response following elevation with the crestal osteotome technique in human cadavers. Int J Oral Maxillofac Implants. 2001;16(6):833-840. 